\title{
LINGUA(GEM) SOB DUAS PERSPECTIVAS TEÓRICAS
}

\author{
LINGUA (GEM) IN TWO THEORETICAL PERSPECTIVES
}

Lidiomar José Mascarello ${ }^{1}$

Mestrando do Programa de Pós-graduação em Linguística - UFSC-CAPES

“A liberdade consiste na possibilidade de optar.”

Saussure

\section{Resumo}

Destacaremos nesse breve percurso teórico dois olhares possíveis para esse fenômeno, língua(gem) - que é tão natural e ao mesmo tempo tão complexo de ser explicado e entendido. De um lado, questões psíquicas individuais, como um processo evolutivo que opera em escala de tempo e que depende da maturação dos processos neurais e de toda rede neuronial e da capacidade inata do sujeito, ou seja, uma visão com tendências mais cognitivista, e por outro, da exposição à interação sócio-ambiental, de cunho interacionista, pois, acreditamos que são complementares e não restritivas ou excludentes.

Palavras chave: Linguagem. Cognitivismo. Interacionismo.

\begin{abstract}
We will highlight in this short theoretical journey two possible views for the language phenomenon, which occurs very naturally: yet it is at the same time very complex to be explained and understood. One view of individual psychic features as an evolutionary process that operates in scale of time and that depends on the maturation of neural processes and the whole neural network within the individual innate capacity, which is a cognitive view with connective tendencies. Another view is the exposition to socioenvironmental interaction, an interactionist view. We do believe that both views complement each other and in no way are restrictive or excluding.
\end{abstract}

Keywords: Language. Cognitive. Interactive.

\section{INTRODUÇÃO}

No final do século XIX, inicio do XX, as ciências que se ocupavam da linguagem direcionavam seus olhares principalmente para os estudos da linguística comparativa e para fatos isolados, geralmente fonéticos. Não havia estudos aprofundados sobre sistemas propriamente ditos, mas sim sobre evolução de palavras, suas origens e processos.

\footnotetext{
${ }^{1}$ lidiomarjose@gmail.com.
} 
No século XX, com o desenvolvimento das ciências físicas, principalmente da física acústica, constata-se o desenvolvimento de diversos aparelhos com a capacidade de proporcionar medidas detalhadas dos fenômenos sonoros e com capacidade de descrever minuciosamente os sons da fala.

Esse progresso leva Saussure a se perguntar se esse é o único ponto de vista a ser considerado pelos linguistas, se apenas o físico importa, e conclui que não, que há princípios psicológicos muito significativos imbricados nos sistemas linguísticos. Questiona também como as pessoas se entendem se a fala é tão heteróclita. Tais questionamentos, entre outros, suscitam novos estudos e novas perspectivas em relação à língua, despontando assim a linguística ${ }^{2}$ moderna.

Destacaremos nesse percurso teórico dois olhares possíveis para esse fenômeno, língua(gem) - que é tão natural e ao mesmo tempo tão complexo de ser explicado e entendido. De um lado, questões psíquicas individuais, como um processo evolutivo que opera em escala de tempo e que depende da maturação dos processos neurais e de toda rede neuronial e da capacidade inata do sujeito, ou seja, uma visão basicamente cognitivista, e, por outro, a exposição à interação sócio-ambiental, de cunho interacionista, pois, acreditamos que são complementares e não restritivas ou excludentes. Em síntese, podemos definir linguagem sob dois níveis: O primeiro relaciona-se com a biologia humana e o segundo com as interações sociais entre indivíduos.

\section{PRIMEIRO OLHAR, “AMOR À PRIMEIRA VISTA”}

Engraçado, se temos a expressão "amor à primeira vista”, é possível termos amor à segunda, terceira, quarta vista e assim por diante, mas parece que não é comum ouvirmos isso. Pela estrutura da língua parece que não haveria problema, mas há alguma coisa, um "acordo social” talvez, fazendo com que pareça estranho ${ }^{3}$

Para nossa fundamentação teórica focada na individualidade, no desenvolvimento neuronial e na capacidade inata do sujeito, tomaremos como base pesquisadores de neurociências como Stemmer (1999) e Matlin (2004); linguistas como Chomsky (2002) e alguns conceitos de Dehaene (2007) que é psicólogo cognitivista. Sob o olhar sócioambiental tomaremos por base o grupo soviético coordenado principalmente por Vygotsky (2001). Aproveitaremos também alguns conceitos de Luria (1985), um dos fundadores da neurolinguística que deu importante contribuição para o conhecimento do funcionamento do cérebro, particularmente a região frontal, defendendo a intercomunicação dos indivíduos; por fim, alguns conceitos de Bakhtin (1986).

Segundo a corrente comportamentalista, a linguagem é uma manifestação comportamental com, pelo menos, duas propriedades. A primeira tem relação com a criação arbitrária de conexões entre a possibilidade de enviar ou receber sinais convencionais de fatos internos ou externos ao sujeito; a segunda relaciona-se com a

\footnotetext{
${ }^{2}$ Informações baseadas nos Manuscritos de Saussure, em curso apresentado por Leonor Scliar Cabral, Fonte: BOUQUET; ENGLER Écrits de linguistique générale par Ferdinand de Saussure. Paris: Gallimard, 2002

${ }^{3}$ Comentário e observação do autor.
} 
possibilidade de combinar esses sinais com outras convenções, permitindo generalizações e aplicação de regras, do ponto de vista cultural, realmente podem ser dadas explicações em termos de propósito de longo alcance e utilidade de que a língua é aprendida e é uma manifestação desse aprendizado (MATLIN, 2004). No entanto, não podemos esquecer que muitas das habilidades humanas são produtos da evolução biológica e de natureza geneticamente determinada. Por exemplo, a voz, a sua produção e a produção da fala são uma atividade de extrema complexidade neurológica, com operações de sincronizações musculares de milésimos de segundo. Operações de precisa coordenação motora de músculos do aparelho fonador que requerem um aparato neurológico de refinado desenvolvimento. Uma das mais importantes reflexões a respeito da raiz neurológica da atividade produtora da linguagem verbal é o estudo de Erich Lenneberg. Em seu livro sobre os fundamentos biológicos da linguagem, Lenneberg considera o ritmo como o primeiro elemento constitutivo da fala humana. Assim declara:

\begin{abstract}
"É conhecido há muito tempo que a ritmicidade do cérebro dos vertebrados ou do tecido nervoso central em geral é o verdadeiro motor para muitos movimentos rítmicos que se encontram entre os vertebrados. Se a nossa hipótese estiver correta, a mecânica motora da fala e provavelmente também da sintaxe, não constituirá nenhuma exceção a esta generalização. No homem, o motor rítmico serve para uma atividade altamente especializada, ou seja, para a fala." (LENNEBERG, 1972, p. 151). ${ }^{4}$
\end{abstract}

Com o desenvolvimento de novas técnicas de imagens, especialmente a tomografia por emissão de pósitrons (PET) e o aperfeiçoamento das técnicas de ressonância Magnética (MRI) que permitem observar, em tempo real, imagens da fisiologia associada com o processo de aprendizagem (MATLIN, 2004, p. 3/7), é possível observar, por exemplo, regiões específicas do cérebro sendo ativadas, quando atividades de leitura são efetuadas, bem como os neurônios e sua intrincada rede de células (RAICHLE, 1999), organizando-se e coordenando suas tarefas.

Essas novas técnicas revelam que o cérebro é um sistema aberto auto-organizável, moldado pela sua interação com objetos e eventos. Ao deparar-se com novos eventos, os mecanismos moleculares do cérebro se ajustam à nova realidade, o que alguns pesquisadores definem como plasticidade neuronal.

De acordo com essas pesquisas, podemos observar e visualizar cada parte do cérebro vivo em ação, do maior circuito até a sinapse no diminuto espaço entre neurônios. É possível registrar a atividade elétrica de uma única molécula no cérebro (ELIOT, 1999, p. 7-8).

Podemos, por exemplo, visualizar algumas áreas cerebrais em ação diante de alguns eventos que envolvem a linguagem: na figura 01, o individuo ao ver palavras ativa áreas cerebrais do Lobo occipital, na figura 02, ao ouvir palavras aciona a região do Lobo

\footnotetext{
${ }^{4}$ Essa é uma tradução feita por Norval Baitello Junior, professor doutor em Ciências da Comunicação pela Universidade Livre de Berlim. Disponível em: http://www.radioeducativo.org.br/1024/..\%5Cartigos\%5Couvir.pdf .
} 
temporal, na figura 03, ao passar a produzir palavras aciona principalmente o Lobo parietal e na figura 04, ao proferir verbos aciona principalmente o Lobo frontal.

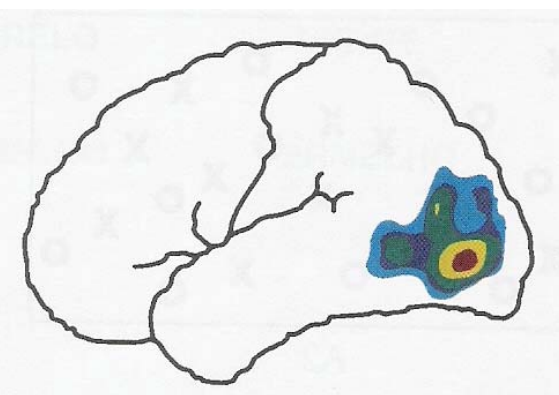

FIGURA 1. $1^{\circ}$ Nível, Visual (Vendo Palavras)

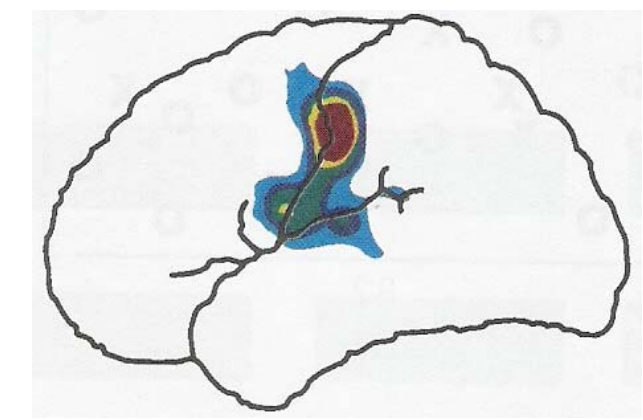

FIGURA 3. $3^{\circ}$ Nível, (Falando Palavras)

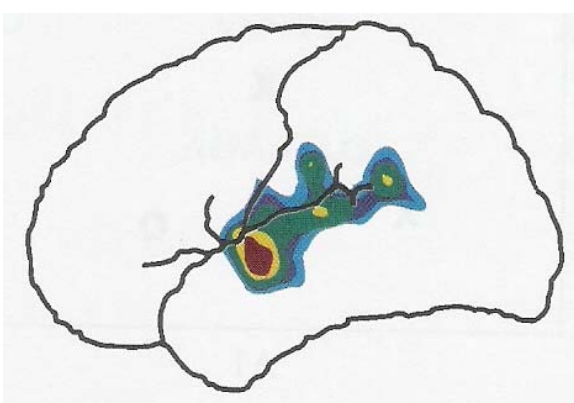

FIGURA 2. $2^{\circ}$ Nível, Auditivo (ouvindo Palavras)

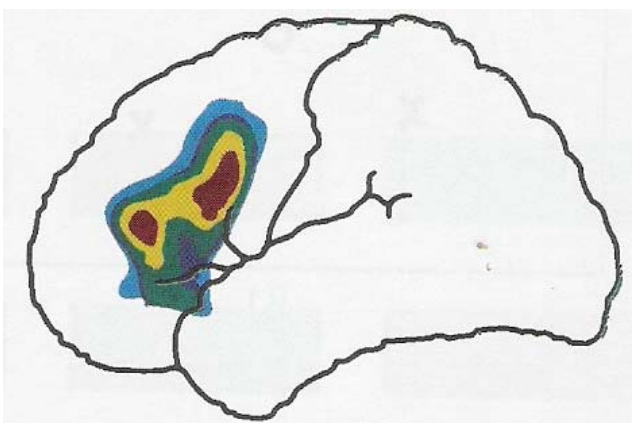

FIGURA 4. $4^{\circ}$ Nível, Produzindo Verbos

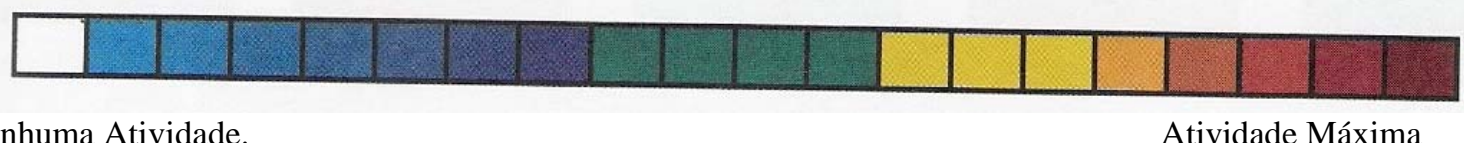

FIGURA 5. Legenda.

Através dessas imagens podemos perceber que realmente ocorrem eventos cerebrais diferenciados quando nos defrontamos com diferentes aspectos da linguagem (MATLIN, 2004).

Como se pode ver, daí resultam caminhos diferenciados para a abordagem linguística, pois estão envolvidos aspectos como a representação dos sons, diversos níveis de significados, aspectos gramaticais, fatores sociais e outros.

A estrutura sintagmática de uma sentença é constituída por uma hierarquia a partir de suas unidades menores, os constituintes: esses não são apenas palavras colocadas lado a lado, isto é, não temos apenas uma cadeia de palavras, mas sim, uma relação complexa entre os elementos de uma sentença. De acordo com as novas pesquisas de 
neurociências, essas relações são percebidas por diferentes partes de nosso cérebro (MATLIN, 2004, p. 188).

$\mathrm{Na}$ cadeia sintagmática, um termo passa a ter valor em virtude do encontro que estabelece com aquele que o precede ou lhe sucede, ou a ambos, visto que um termo não pode aparecer ao mesmo tempo que outro, em virtude do seu caráter linear. Em "Hoje fez frio", por exemplo, não podemos pronunciar a sílaba je antes da sílaba ho (Jeho!), nem ho ao mesmo tempo que je: é impossível. É essa cadeia fônica que faz com que se estabeleçam relações sintagmáticas entre os elementos que a compõem. Como a relação sintagmática se estabelece em função da presença dos termos precedente e subsequente no discurso, Saussure a chama também de relação in præesentia.

Por outro lado, se dissermos "Hoje fez frio" fora do discurso, isto é, fora do plano sintagmático, podemos dizer hoje pensando em opô-lo a outro advérbio, amanhã, por exemplo, ou fez em oposição a faz, e frio a calor. Com isso, estabelecemos uma relação paradigmática associativa ou in absentia, porque os termos ontem, faz e calor não estão presentes no discurso. São elementos que se encontram na nossa memória de falante "numa série mnemônica virtual", (p. 143). O paradigma funciona como uma espécie de "banco de reservas" da língua, um conjunto de unidades suscetíveis de aparecer num mesmo contexto. Desse modo, as unidades do paradigma se opõem, pois uma exclui a outra: se uma está presente, as outras estão ausentes. É a "chamada oposição distintiva", que estabelece a diferença entre signos como gado e gato ou entre formas verbais como estudava e estudara, formados respectivamente a partir da oposição sonoridade / não-sonoridade e pretérito imperfeito / mais-que-perfeito. A noção de paradigma suscita, pois, a idéia de relação entre unidades alternativas. É uma espécie de reserva virtual da língua (CARVALHO, 2003).

Podemos perceber, então, que a linearidade das palavras não é uma fila indiana aleatória, seja na fala ou na escrita: elas estão assim dispostas, pois obedecem a uma estrutura subjacente, assim como as relações associativas não são constituídas por aproximação, mas porque a nossa mente/cérebro percebe que os termos apresentam algo em comum.

Ao analisar o circuito de fala, proposto por Saussure (2008, p. 19) podemos afirmar que um conceito estará associado no cérebro a uma imagem acústica correspondente e esse evento que se dá é inteiramente psíquico, seguido logo após por um evento fisiológico, "o cérebro transmite aos órgãos da fonação um impulso correlativo da imagem; depois as ondas sonoras se propagam.” (SAUSSURE, 2008, p.19).

Stemmer (1999), ao investigar a organização neurofuncional da linguagem, afirma que as habilidades de comunicação dependem também de habilidades pragmáticas da linguagem, que há articulação entre corpo (individuo/cérebro) e meio ambiente.

O cérebro, ou elementos dele, como já mencionamos, são decisivos ao se tratar de linguagem. Para Chomsky, o "cérebro tem um componente denominado de faculdade da linguagem, que se dedica à língua e ao seu uso. Para cada individuo, a faculdade da linguagem tem um estado inicial determinado pela capacitação biológica” (2002, p.149). 
Segundo Chomsky (2002, p. 31), "a faculdade da linguagem pode perfeitamente ser considerada um órgão da linguagem.” Assim como se fala em sistema visual, sistema imunológico ou sistema circulatório como órgão do corpo.

A maneira como isso acontece continua a ser algo remoto para pesquisa, mas podemos investigar o estado inicial geneticamente determinado da faculdade da linguagem de outros modos. É evidente que cada linguagem é resultado da inter-relação de dois fatores: o estado inicial e o curso da experiência. Podemos conceber o estado inicial como um sistema de aquisição da linguagem, que toma a experiência como input e fornece a língua como output - um output que é internamente representado na mente/cérebro. (CHOMSKY, 2002, p.31

Sabe-se que tanto os dados do input quanto os de output são possíveis de serem analisados e estudados e desses estudos pode-se concluir que há diferenças significativas entre ambos, mas que estão intimamente ligados, pois são partes integrantes de um sistema, de tal forma que é muito difícil tentar explicá-los isoladamente: de certa forma eles fazem parte da organização funcional humana (MATLIN, 2004)

Dado que consideramos as afirmações do autor relevantes sobre as propriedades da linguagem e acreditamos que efetivamente em nosso cérebro há um espaço dedicado à língua e ao seu uso e que a faculdade da linguagem depende de um estado inicial determinado pela capacitação biológica, acredita-se que a linguagem é uma propriedade humana comum, como ser bípede, por exemplo. E é esse estado inicial que possibilita a aquisição de qualquer língua: uma criança nascida no Brasil fala português, mas, se a mesma criança nascesse na China, falaria chinês, ou seja, existe um constructo interno que possibilita esse evento.

Segundo Dehaene, “Atrás de cada leitor se esconde uma mecânica neuronial admirável de precisão e eficácia, da qual começamos a compreender a organização” (2007, p.04, trad. de Scliar-Cabral), mas podemos inferir que essa mecânica neuronial não existe apenas na área da leitura, mas cada aspecto da linguagem tem sua organização neuronial.

Muitos dos neurocientistas e dos linguistas conexionistas e cognitivistas aderem a um modelo implícito do cérebro que denominaria o da plasticidade generalizada.De acordo com eles, o cérebro é um órgão flexível e maleável que se adapta às exigências de sobrevivência do indivíduo e da espécie, restrito, porém aos limites impostos por sua própria constituição. Para Dehaene, ao examinar a organização cerebral dos circuitos da leitura, é possível constatar que é falsa a imagem de um cérebro virgem, infinitamente maleável e que se contentaria em absorver os dados de seu ambiente cultural.

Nosso cérebro é evidentemente capaz de aprendizagem, sem o que não poderia incorporar as regras próprias da escrita latina, japonesa ou árabe. Mas esta aprendizagem é limitada. Em todos os indivíduos, em todas as culturas do mundo, a mesma região cerebral, com diferenças mínimas de milímetros, intervém para decodificar as palavras escritas. Seja a leitura em francês ou chinês, a aprendizagem 
da leitura percorre sempre um circuito idêntico. (DEHAENE, 2007, p. 06, trad. de Scliar-Cabral)

Na base destes dados, Dehaene apresenta outro modelo, radicalmente oposto ao do relativismo cultural que denomina "reciclagem neuronial".

De acordo com esta hipótese, a arquitetura de nosso cérebro é
estreitamente enquadrada por fortes limites genéticos. Contudo, os
circuitos do córtex visual dos primatas possuem uma certa margem de
adaptação ao ambiente na medida em que a evolução os dotou de
uma plasticidade e de regras de aprendizagem. Os mesmos neurônios
que reconhecem a forma dos rostos ou das mãos podem do mesmo
jeito direcionar suas preferências a fim de responder a objetos
artificiais, a formas fractais ou mesmo às letras (Fractais (do latim
fractus, fração, quebrado) (DEHAENE, 2007, p.07 trad. de Scliar-
Cabral)

Portanto, podemos considerar que nosso cérebro se adapta ao ambiente cultural, e não absorve cegamente tudo o que lhe é apresentado, ou o que nossos olhos conseguem captar. O cérebro não é constituído de circuitos virgens hipotéticos, e nem se trata de uma tabula rasa onde se acumulam construções culturais: é um órgão estruturado que dá significado ao novo na interface com o velho. "Para aprender novas competências, reciclamos nossos antigos circuitos cerebrais de primatas - na medida em que tolerem um mínimo de mudança” (DEHAENE, 2007, p.07 trad. de Scliar-Cabral). E nesse processo a linguagem vai se constituindo pela entrada e saída de informações, mas para isso acontecer há um refinado processamento interno em que as redes neurais estão constantemente ativadas através das trocas sinápticas.

\section{SEGUNDO OLHAR, OUTRA PERSPECTIVA}

Sob algumas influências do Materialismo Histórico e Dialético, dentre outras, a corrente sociocognitiva vê e estuda a linguagem como algo de natureza social que deve ser internalizado pelo individuo: e o homem através de suas transformações, inclusive da linguagem, faz com que a natureza sirva a seus propósitos. Essa interação homem/ambiente, através de instrumentos, constrói significações, utilizando signos, em especial, a linguagem verbal, elaborada pela sociedade ao longo da história, mudando e transformando seu nível cultural.

Nessa perspectiva a função da linguagem é a comunicação. A linguagem é, antes de tudo, um meio de comunicação social, de enunciação e compreensão. Na linguagem estão associadas às funções da comunicação e do pensamento. Para Vygotsky (2001, p.11) "o significado da palavra é uma unidade dessas duas funções da linguagem, comunicação e pensamento.”

Segundo o mesmo autor, a aquisição da linguagem pela criança modifica suas funções mentais superiores: ela dá uma forma definida ao pensamento, possibilita o aparecimento da imaginação, o uso da memória e o planejamento da ação. Neste sentido, a linguagem sistematiza a experiência direta dos sujeitos e, por isso, adquire uma função central no desenvolvimento cognitivo, reorganizando os processos que nele estão em andamento. 
Todas as funções psíquicas superiores são processos mediados, e os signos constituem o meio básico para dominá-las e dirigi-las. O signo mediador é incorporado à sua estrutura como parte indispensável, na verdade a parte central do processo como um todo. Na formação de conceitos, esse signo é a palavra que, em princípio, tem papel de meio na formação de um conceito e, posteriormente, torna-se o seu símbolo (VYGOTSKY, 2001, p. 164).

Para Luria e seu grupo de estudos, a atividade mental da criança é resultado da sua relação com o meio, em outras palavras, a atividade mental humana desenvolve-se em condições de perfeita comunicação com o meio, através do qual a criança adquire experiência com os adultos, mediante a prática conjunta e a linguagem. A linguagem, por sua vez, intervém no processo de desenvolvimento da criança desde os primeiros meses de vida. Ao nomear os objetos e definir as suas associações e relações, o adulto cria novas formas de reflexão na realidade da criança, bem mais profundas e complexas do que as que ela poderia formar através da experiência individual.

O processo de transmissão do saber e a formação de conceitos fazem parte do processo central do desenvolvimento intelectual infantil e é por meio dele que o adulto influi na criança. Por isso, tanto para Vygotsky quanto para Luria, os processos mentais infantis são produto da intercomunicação da criança com o meio, bem como a aquisição de experiências comuns transmitidas pela palavra passam a ser princípios centrais em suas pesquisas.

O intercâmbio verbal entre criança e adultos muda o conteúdo e a forma da atividade consciente da criança. Essa intercomunicação tem um significado decisivo, por que a aquisição de um sistema linguístico supõe a reorganização de todos os processos mentais da criança. A palavra passa a ser um fator que dá forma à atividade mental, aperfeiçoando o reflexo da realidade e criando novas formas de atenção de memória e de imaginação, de pensamento e de ação. A função básica da palavra é indicar o objeto correspondente no mundo externo, tornando-se, desta forma, essencial na formação dos processos mentais. Assim, as primeiras palavras da mãe ao nomear distintos objetos, têm uma importante influência, pois isolam as propriedades essenciais do objeto $e$ inibem as menos essenciais. (LURIA, $1985^{5}$, correções em negrito pelo autor do presente artigo)

Nessa mesma linha de raciocínio, o autor defende a idéia de que os conceitos científicos adquiridos no processo de aprendizagem da criança, que são formulados verbalmente com a mediação do professor, só serão nomeados à medida que a criança for percebendo a necessidade de uso e a validade dos mesmos; com isso, a criança passa a adquirir a consciência sobre os conceitos muito antes de sua nomeação.

O autor enfatiza que, na formação dos conceitos comuns espontâneos ou do cotidiano que se formam a partir da atividade prática e da experiência figurada direta, predominam as relações circunstanciais concretas e que os conceitos científicos se

5 Disponível em: <http://www.geocities.com/eduriedades/alexanderluria1.html.> Acesso em 16, jun 2009. 
formam com a participação das operações lógico-verbais, construindo assim as relações lógicas abstratas.

Em outras palavras, podemos dizer que a influencia das palavras na formação dos processos mentais não se limita a reorganizar a percepção, mas que a palavra do adulto direcionada à criança é de certa forma um regulador de conduta e que a partir dela a criança desenvolve uma longa cadeia de formação de aspectos complexos de sua atividade consciente e voluntária.

Para Bakhtin, no livro Marxismo e Filosofia da linguagem, esse processo de formação acontece por influências ideológicas: os signos ideológicos não são apenas sombra da realidade, mas são representações da própria realidade. Afirma que a "ideologia é um fato de consciência”. Segundo Bakhtin, os signos só emergem a partir de um processo de interação entre uma consciência individual e uma outra, e a própria consciência individual está repleta de signos. "E todo fenômeno que funciona como signo ideológico tem uma encarnação material, seja como som, como massa física, como cor, como movimento do corpo ou como outra coisa qualquer” (BAKHTIN, 1986, p. 33/34).

Bakhtin afirma ainda que a linguagem é o lugar privilegiado de manifestação da ideologia “[...] A palavra é o fenômeno ideológico por excelência. A realidade toda da palavra é absorvida por sua função de signo. [...] A palavra é o modo mais puro e sensível de relação social.” (BAKHTIN, 1986, p. 36)

De fato, se olharmos em nossa volta, podemos observar que a palavra faz parte do conteúdo de quase todas as formas de atividade humana e estas interferem na formação da percepção e da memória, no estímulo e na ação. Com o surgimento de novas tecnologias que permitem perceber a ação das palavras no cérebro, a percepção e a atenção, a memória e a imaginação, a consciência e a ação deixam de ser consideradas propriedades mentais mais simples e começam a ser entendidas como produto de formas sociais complexas dos processos mentais da criança, como complexos "sistemas de funções" ${ }^{6}$ que resultam do desenvolvimento da atividade infantil nos processos de intercâmbio.

\section{CONSIDERAÇÕES FINAIS}

Como podemos observar, com o que tentamos apresentar até aqui, a natureza da linguagem pode ser vista, analisada e compreendida sob diferentes aspectos e diferentes pressupostos teóricos.

De um lado temos uma perspectiva mais formal e estrutural e do outro uma mais funcional. No primeiro percebemos que a língua(gem) é um fenômeno mental que se incorpora a um saber individual proveniente de uma herança genética que se manifesta sem depender exclusivamente do contexto, considerando portanto a língua(gem) como objeto formal mais abstrato, estruturada em proposições mais abstratas e categorias mais descritivas organizada em níveis sintáticos, semânticos mais autônomos. No segundo, a língua(gem) é constituída em uma interação íntima entre mente e social,

\footnotetext{
${ }^{6}$ Disponível em: <http://www.geocities.com/eduriedades/alexanderluria2.html.> Acesso em: 16, jun de 09.
} 
onde o uso da linguagem na sociedade constitui/forma a mente. Nessa perspectiva a língua(gem) é externa ao individuo, é um instrumento de interação social que depende de competência comunicativa organizada a partir da função e da estrutura dos enunciados e dos valores a eles atribuídos.

Sem estruturas inatas não há efeito do ambiente externo no processo de constituição da língua ou da faculdade da linguagem e, se a herança genética fosse suficiente para o desenvolvimento integral do sujeito, cada um poderia viver isoladamente e sem depender do outro, sem se comunicar com os outros e ainda assim desenvolver-se plenamente. Acreditamos que todos esses elementos são complementares e não excludentes e que é na interrelação mente/cérebro, individual/social que o sujeito se constitui e se desenvolve cognitivamente.

Cada indivíduo faz seu percurso e adquire determinado estado cognitivo de acordo com sua capacitação biológica, suas interações com o ambiente e ainda com as interações dos outros sistemas da mente (articulatório, perceptivo, conceptual, intencional, etc.), tornando-se assim mais qualificado e com maior capacidade cognitiva, tendendo a estar mais integrado ao meio cultural que prioriza o conhecimento.

\section{REFERÊNCIAS}

BAKHTIN, M. Marxismo e Filosofia da Linguagem. 3ª ed. São Paulo: Hucitec, 1986.

CARVALHO, C. de. Para compreender Saussure. 12ª ed. Petrópolis: Vozes, 2003.

CHOMSKY, N. Novos Horizontes no estudo da linguagem e da mente. São Paulo UNIESP. 2002.

DEHAENE, S. Les neurones de la lecture. Paris: Odile Jacob 2007. Traduzido por Leonor Scliar Cabral.

ELIOT, L. What's Going on in There? New York: The Penguin Press, 1999.

LENNEBERG, E. (1967) “Biological Foundations of Language”.N. York: J. Wiley. (trad. alemã: Biologische Grundlagen der Sprache. Frankfurt: Suhrkamp. 1972).Disponível em: http://www.radioeducativo.org.br/1024/..\%5Cartigos\%5Couvir.pdf. Acesso em 24, agosto, 2009

LURIA. A. R. Autor e sua história. Disponível em:

$<$ http://www.geocities.com/eduriedades/alexanderluria1.html.> Acesso em 16, jun de 09.

LURIA. A. R. O desenvolvimento dos hábitos culturais da criança. Disponível em: <http://www.geocities.com/eduriedades/alexanderluria2.html.> Aceso em: 16, jun de 09. 
LURIA, A. R.; YODOVICH, F. I. Linguagem e desenvolvimento intelectual na criança. Porto Alegre: Artes Médicas, 1985

MARCUS, E. R. "Visualizing the Mind.” The Scientific American Book of the Brain. New York: The Lyons Press, 1999, pp. 43-44.

MATLIN,W. M. Psicologia Cognitiva. Rio de Janeiro:LTC. 5a ed. 2004.

SAUSSURE, F. de. Curso de Linguística Geral. São Paulo: Editora Cultrix. ed. 30a ${ }^{\text {., }}$ 2008.

STEMMER, B. et al. Handbook of neurolinguistics. San Diego: CA Academic Press. 1999.

VYGOTSKY, L. S. A Construção do Pensamento e da Linguagem. São Paulo:

Martins Fontes. 2001 